\title{
Paradigms, Approaches and Principals of Knowledge Management
}

\author{
Jelena Davidova ${ }^{1} \mathrm{PhD}$; Irena Kokina ${ }^{2} \mathrm{PhD}$ \\ Daugavpils University, Latvia \\ jelena.davidova@du.lvㅜㄹ ${ }^{1}$ irena.kokina@du.lv²
}

\begin{abstract}
This article is the continuing of the theoretical research in the field of knowledge management. The aim of this study is to review the conceptual foundations of the knowledge management paradigms, approaches and principals in the context of its application in at the local community level. The authors give an overview of the knowledge management paradigms, approaches and principals. By analysing the different conceptions, the authors have come to the conclusion that knowledge cannot be directly managed; it can only be indirectly managed through the carriers of the knowledge - the people (through human resource management), the technology (through information management and information technology management) and the interaction between them (information flows and communication). By analysing top-down and bottom-up approaches the authors stress that the people are the primary source of knowledge while technology is the secondary source; however, technology is necessary for the orderly storage, retrieval, and sharing of knowledge. The authors also write about application of knowledge management principles at local community level: a learning community and organisation build collaborative relationships in order to draw strength from the diverse knowledge, experience, capabilities.
\end{abstract}

Keywords: knowledge management, paradigms, approaches and principals, local communities, adult education.

\section{Introduction}

The key factor in the knowledge-based society is the generation and exploitation of knowledge. Within global development, knowledge management is about utilizing and leveraging what is already known to work to achieve the greatest impact and improve outcomes in organizations. Knowledge management is the art of transforming information and intellectual assets into enduring value for an organisation's 'clients' and its people.

Knowledge management is a concept and a term that arose approximately two decades ago, roughly in 1990. Quite simply one might say that it means organizing an organization's information and knowledge holistically (Davidova, Kokina, Zarina, 2014). The desire to use scientific knowledge appropriately and effectively for human development has enhanced the development and further refinement of knowledge management methodologies (paradigms and approaches) and principles.

In terms of organization as a knowledge system and knowledge as competitive resources, most researchers (Probst, Raub, Romhardt, 2000; Shin, Holden, Schmidt, 2001) look at knowledge management as a process. In this context knowledge management also consists of an interaction procedure linking up individual knowledge to create social knowledge: this procedure includes creation, storage, distribution, and application, as well as becomes a controlled implementation aspect of organizational strategy and vision.

Scientists and practitioners have developed and continue to refine methodologies of knowledge management with the aim to implement it into practice of public organisations and local communities (Davenport, 1996; Nonaka, 2007; Probst, Raub, Romhardt, 2000; Shin, Holden, Schmidt, 2001; Tiwana, 2002; Wenger, 1998). However, it is important to analyse different conceptions of paradigms, approaches and principals in the prism of its application at local community level.

The aim of this study is to review the conceptual foundations of knowledge management paradigms, approaches and principals in the context of its application at local community level.

\section{Methodology}

The research undertaken for this article is theoretical and based on a study and synthesis of the existing literature on the topic. The scope of the literature consulted includes classic management literature and articles specifically on knowledge management. Knowledge is a transdisciplinary field and indeed incorporates many disciplines such as philosophy, economics, management, information technology, 
human resources, psychology, sociology, communication studies and many more. The focus of this article will be on the managerial and business aspects of knowledge management.

\section{Results and Discussion}

\section{Paradigms of knowledge management}

The paradigm provides researchers and practitioners with a shared perspective on their field. In knowledge management the fundamental entity is knowledge, which has traditionally been the subject of epistemology and philosophy of science (Essers, Schreinemakers, 1997, 26). Some synonyms for paradigm are conceptual framework, interpretative framework, mental model and shared vision.

I.Nonaka (2007) notes that the managerial philosophy in the West conceives the organisation as a machine for information processing (thus a paradigm founded in rationalism). The only useful knowledge is formal and systematic (thus declarative and procedural knowledge), knowledge that is or comes from hard data, formulae, codified procedures and universal principles which corresponds to the idea of eternal truths of R. Descartes, B. Spinoza, D. Hume and I. Kant. Knowledge is explicit, expressed in numbers and words and easily communicated.

On the other hand, the Eastern paradigm is based on soft and qualitative elements where knowledge is tacit and resides in the individual's experiences, beliefs and perceptions. Knowledge is acquired through learning from direct experience and trail and error. I. Nonaka argues for the Eastern paradigm (founded in empiricism) with regard to knowledge creation and management that is intuitive and subjective. Furthermore, the organisation is seen as a living organism and flourishes in redundancy - the conscious overlapping of company information, business activities and managerial responsibilities. He stresses that management in the West must discard the notion that knowledge can be acquired and taught, by manuals, books and lectures.

The authors of this article are not in complete agreement with either of these paradigms of management. The synthesis arising from Western and Eastern paradigms would be the ideal management approach and there are quite a few authors who agree in the literature. This synthesis represents the paradigm shift that must take place in management to accommodate the subjective nature of knowledge.

There are three paths to achieve synthesis presented in this article. Firstly, M.J. Wheatley (1994) contends that we live in a world that still largely has 'Newtonian' type thinking of rationality, linearity, order, hierarchy. However, there are useful metaphors and images for knowledge management in organisations to be found in the 'new science' of chaos theory, quantum mechanics, self-organising systems, complexity theory, non-linear systems. Thus, information (not to even mention knowledge) cannot be controlled and much less managed. She proposes that information should be encouraged (reminiscent of the redundancy in the Eastern paradigm) and the principles of self-organising systems should be allowed to take over.

Secondly, in terms of system thinking views amongst others business and human endeavours as systems where all components are joined by interconnections and as such are "bound by the invisible fabric of interrelated actions, which often take years to fully play out their effects on each other" (Senge, 1990, 6-7). But the Western paradigm focusses not on the whole system but only on parts of it, so called 'snapshots' of isolated components of the system and here lies its weakness. The adoption of systems thinking which requires a shift of mind (metanoia) will supplement this weakness. No longer are people separate from the world but connected and that "problems are not caused by someone or something out there [but that] our own actions create the problems we experience" (Senge, 1990, 12-13) (square brackets are authors' own inclusion).

Lastly, information ecology, proposed by T.H. Davenport and L. Prusak (1997), emphasises an organisation's entire information environment. It addresses all of the organisation's values and beliefs about information:

- the corporate culture;

- how people actually use information and what they do with it (behaviour and work processes);

- the pitfalls that can interfere with information sharing (politics);

- what information systems are there already in place (technology). 
The 'information ecology' paradigm is holistic and multidisciplinary, relying on the disciplines of biology, sociology, psychology, economics, political science and business strategy.

Information ecology has four key qualities:

- the integration of diverse types of information (from the biological analogy of species diversity);

- the recognition of evolutionary change (the business environment is continuously changing, therefore, the information needs as well);

- an emphasis on observation and description instead of modelling and prescription;

- focus on people and information behaviour (i.e. not only the providers but also the recipients).

\section{Approaches to knowledge management}

\section{Different analogies with regard to knowledge and organisations}

"Knowledge management is a discipline that promotes an integrated approach to identifying, capturing, evaluating, retrieving, and sharing all of an enterprise's information assets. These assets may include databases, documents, policies, procedures, and previously un-captured expertise and experience in individual workers" (Duhon, 1998, 8).

With regard to knowledge management there are two prominent analogies, namely economics and biology. The economic analogy refers to accumulated knowledge as intellectual capital, as an extension of the concept of capital. Although, the economic analogy is generally favoured by managers due to its economic (and therefore profitable) nature; it is limited somewhat as the analogy is not entirely appropriate: knowledge creation is not the same as labour and knowledge assets is not the same as other assets.

The biological analogy sees the organism on as an organism where the accumulated knowledge is referred to as a corporate memory. The idea of organisational memetic (Price, 1995) builds on the biological analogy: whereas an organism is a creation of genes, an organisation can be seen as a product of the meme (or mental model) acting like a gene resulting in an organisation that self-organises around a set of unexpressed rules and assumptions. The biological analogy is also supported by the metaphor of information as lifeblood and the system through which information is circulated is the circulatory system. Thus, information enables the life of the organism (the organisation) but in itself does not initiate actions in the way knowledge resident in the brain (top management) can.

According to J. Taylor and W. Wacker (1997), the synthesis of economic and biological theory is found in bionomics. They further predict that bionomics will flourish as an academic discipline because as a result of this merging "economic systems will assume the properties of biological ones" (Taylor, Wacker, 1997, 100).

\section{Top-down or bottom-up management?}

According to L. Remeikis (1996), knowledge management can be a 'grass roots' sort of effort without the involvement of senior management or their support. This contrasts with T.H. Davenport (1996) assuming that knowledge management can thrive without support from senior executives is a pitfall. According to him, one might be able to build a little knowledge repository without top management support, but this is unlikely to bring about any real transformations in the organisation.

Surveying 25 firms that had attempted to improve knowledge work processes T.H. Davenport (1996) found that in general, the most effective improvement approaches struck a middle ground between top-down re-engineering of the process and bottom-up design by autonomous knowledge workers.

I. Nonaka and H. Takeuchi (1995) noted that synthesis of these two opposing management approaches to be found in the middle-up-down management process. In middle-up-down management, top management gives the conceptual framework and support and encourage, recognize, and reward openness, systemic thinking, and creativity (Nonaka, 2007). Middle-up-down management is based on teamwork where teams are largely autonomous in interpreting the strategy of top management with top management acting as a catalyst more than a leader: "A more equivocal vision gives employees and work groups the freedom and autonomy to set their own goals. This is important because while the ideals of senior management are important, on their own they are not enough. The best that top managers can do is to clear away any obstacles and prepare the ground for self-organising groups and teams. Then it is up to the team to figure out what the ideals of the top mean in reality" (Nonaka, 2007, 104). 
A comparison of these three approaches and their key characteristics, which is adapted from I. Nonaka and H. Takeuchi (1995), can be seen in Table 1:

Table 1

A comparison of the three management approaches and their key characteristics

\begin{tabular}{|l|c|c|c|}
\hline & Top-down & Bottom-up & Middle-up-down \\
\hline Agent of knowledge creation & Top management & $\begin{array}{c}\text { Entrepreneurial } \\
\text { individual }\end{array}$ & Team \\
\hline Top management role & Commander & Sponsor/mentor & Catalyst \\
\hline $\begin{array}{l}\text { Middle management role } \\
\text { processor }\end{array}$ & $\begin{array}{l}\text { Information } \\
\text { entrepreneur }\end{array}$ & Autonomous leader & Team \\
\hline Accumulated knowledge & Explicit & Tacit & Explicit and tacit \\
\hline Knowledge storage databases & Computerised & Individuals knowledge & Organisational base \\
\hline
\end{tabular}

According to P.C. Murray (1997), there are two typical strategies, in which these management approaches manifest themselves. Business managers (and knowledge management consultants who sell services to them) tend to adopt a top-down viewpoint of knowledge management. They are concerned with what managers have to know and do in order to push their organisations toward leveraging corporate intellectual assets. By contrast, technologists tend to focus on knowledge sharing and re-use, on enabling technology that can be used by all members of an organisation. They believe the right tools will make good things happen and that explicit knowledge, properly modelled, should be our primary concern. The benefits will be spread through the organisation by means of the ripple effect, often unpredictably and even chaotically.

\section{People-centred and technology-centred approaches}

The first approach is the management of people known as human resources. People in this field probably have their education in philosophy, psychology, sociology, and/or business management. They are primarily involved in assessing, changing and improving human individual skills and behaviour. To them knowledge is a process (supporting the subjective nature), a complex set of dynamic skills and know-how that is constantly changing and being adapted. This approach is relatively old and is not growing so fast.

According to K.E. Sveiby (2002), the second approach is the management of technology. People in this field tend to have been educated in computer science and/or information science. They are primarily involved in construction of information management systems (including organisation and retrieval of information from the system), artificial intelligence and implementing groupware solutions amongst others. Knowledge is seen as an object (supporting the objective nature of knowledge) that can be identified and handled in these systems. This approach is relatively new and is growing relatively fast due to developments in IT.

Each of these management approaches can fall on either the individual or organisational level. The technology-centred approach focusses on structural intellectual capital in terms of process management (embedded knowledge) and information management (recorded knowledge) whereas the people-centred approach focusses on human intellectual capital (people management).

Having analysed these two approaches (strongly coupled to the subjective versus objective nature of knowledge) the authors would like to stress that the people are the primary source of knowledge and technology is the secondary source. However, technology is necessary for the orderly storage, retrieval, and sharing of knowledge.

\section{Principles of knowledge management}

Speaking about the principles of knowledge management, R.O. Barclay and P.C. Murray (1997) identify three approaches to organisational knowledge management: the mechanistic, cultural or behavioural, and systematic. G. Probst with colleagues identify the following as the core processes of knowledge management, which also guide its principles: knowledge identification, knowledge acquisition, knowledge development, knowledge sharing and distribution, knowledge utilisation, knowledge retention (Probst, Raub, Romhardt, 2000). 
A.M. Kaniki and M.E.K. Mphahlele referred three kinds of approaches to effect knowledge management (Kaniki, Mphahlele, 2002, 10 - 11):

- the mechanistic approach to knowledge management focuses on the application of technology and associated resources as tools for facilitating access to information, and helps organisations achieve more with less;

- the cultural/behavioural approach, on the other hand, emphasises innovation and creativity, which are important for learning organisations; the introduction of new ways of doing things, of new experiences that force organisations and communities to adopt a holistic view of their relationships with the environment, further influences community and organisational culture;

- the systematic approach uses systems thinking, which incorporates all aspects of knowledge management to ensure continuous evaluation and a sustainable process; this requires the recognition and utilisation of the various cross-disciplines to develop knowledge management systems and processes.

The level and amount of knowledge that an individual, organisation or community possesses at a particular time cannot resolve or facilitate all the problem-solving and decision-making processes encountered in the course of the 'knower's' existence. The implications are that an individual or organisation must be continuously learning, acquiring new knowledge and generating new knowledge, and be aware of who owns appropriate knowledge that is relevant to particular situations. Based on this assumption, the emphasis in today's environment is on learning how to learn and/or changing organisations into learning organisations.

G. Probst (Probst, Raub, Romhardt, 2000) argue that it is vital that knowledge be shared and distributed within an organisation (and community) so that the whole community can use isolated information or experience. Knowledge sharing is the essence of how we bring innovations to change the way the world works and lives. If learning organisations understand this, knowledge will be volunteered without doubt (Kaniki, Mphahlele, 2002). According to D. Snowden (1999), without trust among the members of the community or organisation, it will be impossible to tap the tacit components of the community or organisation's intellectual assets. The key issue is to identify the factors that motivate people within an organisation or community to share their intellectual assets.

Analysing some conceptions about knowledge management, T.H. Davenport (1996) identifies ten principles that govern or can guide knowledge management processes in organisations.

- Knowledge is assets that must be identified, captured, and have value added to it. Knowledge management is an expensive process, which involves knowledge capture and adding value through editing, repackaging and so on. It also involves developing knowledge categorisation through processes such as classification and developing and applying IT infrastructure for storage and distribution.

- Knowledge management is interdisciplinary and aims at dealing with cross-disciplinary problems. Therefore, the effective knowledge management requires a number of solutions involving people and technology. Today's problems are often complex, requiring complex solutions with ideas adapted from several sources, disciplines and communities. No one individual or organisation possesses all the required knowledge and skills.

- Knowledge is associated with power, money and success. Whoever has the know-how for doing something better is bound to 'sell' that knowledge for profit, recognition or simply respect. Therefore, managing knowledge is highly political because it involves determining who has access to and can utilise and derive benefits from the valuable knowledge resources.

- Like every resource in an organisation, knowledge management requires knowledge managers. Key resources in organisations require managers to facilitate their generation, distribution and use. If not appropriately managed, resources can be misused and thus depleted. Collecting and categorising knowledge, establishing knowledge-oriented technology infrastructure and monitoring the use of such knowledge are some of the tasks that knowledge management managers should perform.

- A key element of knowledge management is knowledge sharing within a given environment or community. However, in order to share knowledge effectively for the benefit of the organisation, and its members, and to facilitate productivity, knowledge maps must be generated. Maps of knowledge assets show where and how particular knowledge assets are stored in the organisation.

- Although knowledge management emphasises sharing knowledge, sharing and using knowledge are often unnatural acts. People often keep knowledge to themselves in order to preserve their power and prestige. Organisations have to identify and use effective motivators and motivating techniques to 
facilitate knowledge sharing. At the same time, 'knowers' and generators of knowledge must be assured that they will be appropriately compensated, rewarded and/or recognised for their knowledge.

- Knowledge management means improving knowledge work processes. The organisation must facilitate knowledge generation, utilisation and transfer by putting in place appropriate policies, resources and facilities. It is complex and requires financial, human and material resources.

- Information and knowledge in themselves are not useful unless they are applied to specific situations. Access to knowledge, while important, is not sufficient. To be useful and profitable, knowledge must be applied.

- Knowledge management never ends: knowledge generation, its utilisation and transfer are necessary because new problems and situations arise and require new solutions. The need for new knowledge and its application changes with time; therefore, there is no stage when knowledge is fully managed.

- Knowledge management requires a knowledge contract: human beings are naturally competitive creatures and strive to improve their living conditions. Humans have recognised that money, time, effort, and other resources invested in the creation and/or development of intellectual property or knowledge must be recognised and rewarded. In addition to legal frameworks and laws, human beings depend on conventional practice, moral values, judgement and obligations or ethics in their interaction with one another and in the protection of their rights and those of the community. Therefore, it is important to identify who owns what and has the right to use an individual's knowledge.

\section{Application of knowledge management principles at local community level}

A number of knowledge management activities and initiatives are in place or are taking shape internationally, nationally and regionally. However, it is important to look at the local or community levels and ask the questions: How applicable are knowledge management principles at local community level? Should the knowledge management processes for managing indigenous knowledge in fact be similar to business processes?

Some of the knowledge management principles can be applied to manage certain aspects of indigenous knowledge. Owing to the nature of indigenous knowledge not all of it can be managed like scientific knowledge. In traditional communities, intellectual property is protected through trust and not necessarily through legal frameworks.

E.C. Wenger and W.M. Snyder (Wenger, 1998; Wenger, Snyder, 1999) use the term 'communities of practice', which are groups of individuals with shared interests that come together in person or virtually to tell stories, to share and discuss problems and opportunities, discuss best practices, and talk over lessons learned. Communities of practice emphasize the social nature of learning within or across organizations.

The organization and maintenance of communities of practice is not a simple or easy undertaking. As P. Hildreth and C. Kimble (2004) point out, there are several key roles to be filled, which she describes as manager, moderator, and thought leader. They need not necessarily be three separate people, but in some cases, they will need to be.

For a community of practice some questions that need to be thought about are:

- Who fills the various roles of manager, moderator, and thought leader?

- How is the community of practice managed?

- Are postings open or does someone vet or edit the postings?

- How the community of practice is kept fresh and vital?

- When and how (under what rules) are items removed?

- How are those items archived?

- Who reviews the communities of practice for activity?

- Who looks for new members or suggests that the communities of practice may have outlived its usefulness?

Knowledge sharing and learning within communities are systematic and sophisticated processes. However, this would require many different skills and a great deal of interaction between local communities, the government and knowledge experts. Mutual trust and a working together are very important for the common good among the partners. Y. Merali (2000) uses a metaphor of an ecological community to define a knowledge management community: "In knowledge management, a community of practice is defined as an interdependent group of people inhabiting the same information space, 
interacting with each other through resources and other relationships" (Merali, 2000, 80-81). He identifies three elements that are necessary to develop such communities: a) a clear identity of the community and what it stands for; $b$ ) a sense of belonging and reciprocal attachment among members of the community; c) the concept of self and non-self, that is a shared sense of who and what the parts of the community lie within it and what lies outside.

It is obviously that in the interaction of local communities with the global community there is a need to apply a number of principles for managing indigenous knowledge in order to preserve it, utilise it effectively and protect it. These are the challenges we face and need to address if indigenous knowledge is to be managed effectively for the benefit of all.

We would like to stress that indigenous knowledge is extremely valuable and is increasingly becoming even more valuable to our communities, because the complex problems we are facing today require complex solutions that arise from the utilisation of all forms of knowledge, including indigenous knowledge. T.H. Davenport supposes that most knowledge management principles can be used to manage indigenous knowledge; however, several issues need to be addressed for indigenous knowledge to be effectively managed for the benefit of all. One of the principles of knowledge management, that the management of indigenous knowledge will follow a continuous cycle rather than being a one-off process, is most important for knowledge management in local community: as people share and use knowledge, the categories of required knowledge will change according to individual needs.

\section{Conclusions}

Analysing mentioned conception, we would like to emphasis the most important aspects of knowledge management:

- the core objective of knowledge management is getting the right information to the right people at the right times to help people share experiences and insights, and to improve the productivity of teams;

- knowledge management involves educating people about the techniques of creating, sharing and using knowledge within and outside their community or organisation; in this context it is necessary to construct unique knowledge management environments using both human and technological resources in a complementary way;

- organisations should invest in developing knowledge sharing, distribution techniques and best practices; the application of IT in knowledge networks is crucial in modern society;

- knowledge cannot be directly managed; it can only be indirectly managed through the carriers of the knowledge - the people (through human resource management), the technology (through information management and information technology management) and the interaction between them (information flows and communication). A learning community and organisation build collaborative relationships in order to draw strength from the diverse knowledge, experience, capabilities and ways of doing things that people and communities in general have and use.

Knowledge management is a transdisciplinary process and aims at dealing with cross-disciplinary problems; the synthesis arising from Western and Eastern paradigms would be the ideal management approach: this synthesis represents the paradigm shift that can take place in management to accommodate the subjective nature of knowledge. Nowadays a balance of people-centred and technology-centred approaches is the ideal and each organisation must determine where this balance lies in their situation.

\section{Bibliography}

1. Barclay R.O., Murray P.C. (1997). What is Knowledge Management? Knowledge Praxis. Retrieved from http://www.providersedge.com/docs/km_articles/What_Is_Knowledge_Management.pdf

2. Davenport T.H. (1996). Some Principles of Knowledge Management. Strategy and Business, 1(2). Retrieved from https://www.strategy-business.com/article/8776?gko=f91a7

3. Davenport T.H., Prusak L. (1997). Information Ecology: Mastering the information and knowledge environment. New York: Oxford University Press.

4. Davidova J., Kokina I., Zarina Z. (2014). From Knowledge Management Theories to Practice in Public Organisations: Towards a Transdisciplinary Approach (Theoretical Background). European Scientific Journal, 10 (31), 118-132. 
5. Duhon B. (1998). It's All in Our Heads. Inform, 12 (8), 8-13.

6. Essers J., Schreinemakers J. (1997). Nonaka's Subjectivist Conception of Knowledge in Corporate Knowledge Management. Knowledge Organisation, 24 (1), 24-32.

7. Hildreth P., Kimble C. (2004). Knowledge Networks: Innovation Through Communities of Practice. London / Hershey: Idea Group Inc.

8. Kaniki A.M., Mphahlele M.E.K. (2002). Indigenous Knowledge for the Benefit of All: Can Knowledge Management Principles Be Used Effectively? South African Journal of Libraries and Information Science, 68 (1), 1- 15.

9. Merali Y. (2000). Self-organizing Communities. In S. Rock (Ed.), Liberating Knowledge, 80-87. London: IBWCBL

10. Murray P.C. (1997). Information, Knowledge, and Document Management Technology. Knowledge Management Briefs, 1 (2).

11. Nonaka I. (2007). The Knowledge-creating Company. Harvard Business Review, 69 (6), 96-104.

12. Nonaka I., Takeuchi H. (1995). The Knowledge-creating Company: How Japanese Companies Create the Dynamics of Innovation. New York: Oxford University Press.

13. Price I. (1995). Organisational Memetic: Organisational Learning as a Selection Process. Management Learning, 26(3), 299-318. Retrieved from http://citeseerx.ist.psu.edu/viewdoc/download?doi=10.1.1.475.192\&rep=rep1\&type=pdf

14. Probst G., Raub S., Romhardt K. (2000). Managing Knowledge: Building Blocks for Success. Chichester, England: John Wiley and Sons Ltd.

15. Remeikis L. (1996). Knowledge Management: The Third 'Era' of the Information Age? Info Manage, 3 (10), 1-5.

16. Senge P.M. (1990). The Fifth Discipline: The Art and Practice of the Learning Organization. New York: Doubleday.

17. Shin M., Holden T., Schmidt R.A. (2001). From Knowledge Theory to Management Practice: Towards an Integrated Approach. Information Processing and Management, 37, 335-355.

18. Snowden D. (1999), Liberating Knowledge, CBI Business Guide, 6-19.

19. Sveiby K.E. (2002). Measuring Intangibles and Intellectual Capital. Knowledge Management, 337-354.

20. Taylor J., Wacker W. (1997). Speak the Future. Wired, 6, 100-107.

21. Tiwana A. (2002). The Knowledge Management Toolkit: Orchestrating IT, Strategy, and Knowledge Platforms. ( $2^{\text {nd }}$ ed.). New York: Pearson Education.

22. Wenger E.C. (1998). Communities of Practice: Learning, Meaning and Identity. Cambridge: Cambridge University Press.

23. Wenger E.C., Snyder W.M. (1999). Communities of Practice: The Organizational Frontier. Harvard Business Review, 78(1), 139-145.

24. Wheatley M.J. (1994). Leadership and the New Science: Learning about Organization from an orderly Universe. Berret-Koehler Publishers. 